\title{
Volatility of Dhaka Stock Exchange
}

\author{
Md. Noman Siddikee ${ }^{1} \&$ Noor Nahar Begum ${ }^{2}$ \\ ${ }^{1}$ Assistant Professor of Finance, Department of Business Administration, Past Employer: International Islamic \\ University Chittagong, Bangladesh \\ ${ }^{2}$ Lecturer of Finance, Faculty of Business Studies, Bangladesh University of Professionals, Dhaka, Bangladesh \\ Correspondence: Md. Noman Siddikee, Past Employer: International Islamic University Chittagong, Bangladesh. \\ E-mail: siddikeenoman@gmail.com
}

Received: February 13, 2016

Accepted: April 22, 2016

Online Published: April 25, 2016

doi:10.5539/ijef.v8n5p220

URL: http://dx.doi.org/10.5539/ijef.v8n5p220

\begin{abstract}
We apply GARCH (p, q) and $\mathrm{ARCH}(\mathrm{m})$ model to the daily return of DSE general index (DGEN) ranging from $1^{\text {st }}$ January, 2002 to $30^{\text {th }}$ July 2013 for examining market volatility. Besides, we calculate year wise standard deviation of daily return of DGEN for the same period. The result of $\operatorname{GARCH}(1,1)$ process and standard deviation of the daily return confirms an abnormal volatility episode from 2009 to 2012 . The highest per day volatility was observed in the first half of 2011 in both investigations. The volatility rate found in GARCH $(1,1)$ process is $2.44 \%$ in 2011 followed by $2.00 \%$ and $1.99 \%$ in 2009 and 2012 respectively. The highest standard deviation of return is $2.99 \%$ in 2011 followed by $2.08 \%$ in 2012 authenticate the highest volatile periods of the study. We apply ARCH (m) model in 2004 and 2013 for volatility estimate due to inapplicability of GARCH (p, q) process in those market return. The results of $\mathrm{ARCH}(\mathrm{m})$ model confirm reliable estimates of market volatility, $1.10 \%$ and $1.46 \%$ respectively. This is a part of our total research work where our main focus is to detect the factors affecting market volatility and its spillover effects in emerging markets.
\end{abstract}

Keywords: volatility, DSE, long term variance

\section{Introduction}

Stock Market is one of the important barometers of an economy and stock prices are the indicator of how the economy is moving. Volatility in stock prices is regarded as the major challenges for sustainable growth and development of the country's capital markets. Volatility is a measure for variation of price of a financial instrument over time, and as much the markets are volatile, it creates risk which is associated with the degree of dispersion of returns around the average. Stock market in developing countries are many instances not well regulated, monitored and structured that enhances the chance of volatility of stock price. Lack of efficient regulation over the security markets and business is one of the main reasons for stock market volatility. In recent collapse of stock markets, the most sighted factors are demand and supply of the stocks, dividend declaration, and declaration of premium, issuing right share, the earning revenue of the company, the reputation of the company, change of rating and the consistency of the company. Various kinds of offer of the company also affect the share prices. Factors which affect stock prices can be divided into two types. Macro factors which include rising interest rates, unanticipated inflationary movement, productivity levels of the industry, political and others may have significant impact on the potential benefits of the company. Stock market always works within a frame work, when this changes due to government intervention, market faces volatility. Besides, changes in economic growth also cause market volatility. In micro factors, change management, availability of raw materials, labor productivity and others can affect the profitability of the company consequently the stock prices also. If investors fail to predict the future reliably, volatility will occur. In such a situation mainly fear factors work to make the market volatile. Another main reason for recent stock market collapse is the dealing behavior of Institutional investors in comparison to small investors.

\subsection{Background of the Study}

Bangladesh stock markets has witnessed two landslide price falls in the last two decade (1996 and 2011). Several regulatory authorities are blaming each other but until today no initiative have been taken to find out the severity of market volatility and explore the reasons of recent stock market collapse except some policy research by stock exchange authorities, the central bank and donor organizations (e.g. IMF, World Bank) etc. From this, we 
try to measure the volatility levels of DSE and its trends from January, 2002 to July, 2013. Also this study tried to identify the mostly volatile period from 2002 onwards.

\section{Literature Review}

Basher (2007) empirically examined the time varying risk return relationships and impact of institutional factors (such as circuit breakers) on market volatility of Dhaka Stock Exchange (DSE). Findings suggest four significant return behavior of DSE. (a) Equity returns are serially correlated signifying the stock market inefficiency (b) a significant relationship exist between conditional volatility and market return, however risk return parameters change rapidly from sample to sample and also with the change of data frequency. (C) overall risk-return correlation co-efficient is negative rejecting the standard portfolio theory. This may also imply that emerging markets investors are not demanding more risk premium. (d) Compare to lock-in with circuit breaker mechanism; the later has significant impact on volatility of realized return. Using both parametric and non parametric tests, Bepari et al. (2009) finds the return series of DSE does not satisfy the normality assumption and follow random walk, suggesting inefficient capital markets. A contradictory evidenced found about market efficiency of DSE from the study of Khaled and Islam (2005) who used monthly and daily data of DSE before and after of 1996 crash and examine market efficiency with and without heteroscedasticity adjustment. The empirical results suggest weak form market efficiency of DSE after 1996 market crash. This finding is reverse with the autocorrelation test of the same study which confirms the existence of predictable pattern. To test the weak form market efficiency, Hamid et al. (2010) analyzed monthly return ranging from January, 2004 to December, 2009 of 16 emerging and developed markets in Asia Pacific region. Findings suggest that no markets are weak form efficient and investors can gain profit through arbitrage process across the markets.

Risk return behavior analysis of stock market is more important in any developing countries because most of the investors are risk-averse. The degrees of volatility in stock markets compel them to demand higher risk premium which creating higher cost of capital and slower the economic development, Mala and Reddy (2007). Chowdhury, Mollik and Akhter (2006) finds a relation between stock market volatility with macroeconomic factors but it is not as strong as required by the standard finance theory. A significant relationship exists between stock price volatility and dividend declaration. A number of studies have found a positive relationship (Gordon, 1959; Ogden, 1994; Stevens \& Jose, 1989; Kato \& Loewenstein, 2002; Lee, 1995) with the Dividend payments. A negative relation also exist (Loughlin, 1982; Easton \& Sinclair, 1989) because of tax effect. Officer (1973) shows that aggregate stock volatility has increased during the Great Depression, as did the volatility of money growth and industrial production. He also shows that stock volatility was at similar levels before and after the depression. For recent market volatility of Bangladesh, trade syndication or impact of decision by other regulatory bodies like Bangladesh Bank, is the most significant factors. Besides this, various policy and frequent change of policy of the Government and Bangladesh Bank (tight monetary policy, decision about margin loan, CRR etc.) also affect the stock prices in 2011. From various articles of news paper, it's seen that market monitoring by SEC has also an impact over share prices. Weak growth of remittance inflows and a high outflows lowered the money supply causes the share price to decline. Hassan, Islam, and Basher (1999) find that DSE returns show positive skewness, excess kurtosis and deviation from normality. The DSE volatility tends to be changed over time, and is serially correlated implying stock market inefficiency. They also confirm that a significant relationship between conditional volatility with market returns also exists.

\section{Methodology GARCH (p, q) Model}

We apply GARCH (p, q) model developed by Bollerslev (1986) and Taylor (1987) for year wise volatility calculation. This is an extension of ARCH (m) model which illustrate a linear relationship between past conditional variance with $\mathrm{p}$ lagged conditional variance. This model considers time varying volatility of time series return. Among the GARCH family model, GARCH $(1,1)$ model is the simplest and regularly used for volatility forecasting because it give emphasis on most recent estimates of continuously compounded return square $\left(u^{2}\right)$ and variance rate $\left(\sigma^{2}\right)$. The $\operatorname{GARCH}(1,1)$ process expressed as $\sigma_{n}^{2}=\omega+\alpha_{i} u_{n-1}^{2}+\beta \sigma_{n-1}^{2}$ where, $\omega=\gamma \mathrm{V}_{\mathrm{L}}, \mathrm{V}_{\mathrm{L}}=\frac{\omega}{\gamma}$ and $\gamma=(1-\alpha-\beta), \mathrm{V}_{\mathrm{L}}$ is the long run average variance rate and $\gamma$ is the weight given to $V_{L}$. The $u^{2}$ is the square of the $\log$ return of market variable $\left(S_{i}\right)$ where $u_{i}$ is the daily $\log$ return which is $\ln \frac{s_{i}}{S_{i-1}}$. The basics of logarithmic return is it's time additive nature, can give more precise estimates of 
daily return. $S_{i}$ denotes today's index value whereas $S_{i-1}$ is the previous day's value. The parameter $\alpha$ is the weight assigned to the $\mathrm{u}_{\mathrm{i}}$, which is more on recent observation and less on older observation. The parameter value $\beta$ is the weight given to $\sigma_{\mathrm{n}-1}^{2}$. The $\sum_{\mathrm{i}=1}^{\mathrm{m}} \alpha_{\mathrm{i}}=1$ subject to $\beta$ and $\gamma$ is zero and the sum of parameter value must sum to unity $(\gamma+\alpha+\beta=1)$ which also support the sum of $(\alpha+\beta)<1$ is required for a valid GARCH $(1,1)$ process. Otherwise weight assigned to long term variance $(\gamma)$ will be negative and make the model conflicting for predicting volatility. In that case we have to apply a higher order GARCH model which can be found by setting up different values of $\mathrm{p}$ or q rather than 1. Variance of a time series return using higher $\operatorname{order} \operatorname{GARCH}(\mathrm{p}, \mathrm{q})$ model can be calculate using the following equation. $\sigma_{\mathrm{t}}^{2}=\omega+\sum_{\mathrm{i}=1}^{\mathrm{p}} \alpha_{\mathrm{i}} \mathrm{u}_{\mathrm{n}-\mathrm{i}}^{2}+$ $\sum_{\mathrm{j}=1}^{\mathrm{q}} \beta_{\mathrm{j}} \sigma_{\mathrm{n}-\mathrm{j}}^{2}$. We apply trial and error method putting different values of $i$ and $\mathrm{j}$ to verify the GARCH $(p, q)$ model which shows minimum Schwarz Information Criterion (SIC) value and offer $(\alpha+\beta)<1$. Finally we simplified the volatility calculation formula is $\sqrt{\frac{\omega}{1-\alpha-\beta}}$ using $\operatorname{GARCH}(\mathrm{p}, \mathrm{q})$ model. In our paper we apply GARCH model for changing Volatility of high frequency data. The overall variation can be easily captured by GARCH model.

\subsection{ARCH (m) Model}

An autoregressive conditional heteroskedasticity (ARCH) model was developed by Engle (1982) is used to calculate the yearly volatility where the parameter value of $\operatorname{GARCH}(\mathrm{p}, \mathrm{q})$ process is more than 1 , i. e $(\alpha+\beta)>1$ for different values of $\mathrm{p}$ and $\mathrm{q}$ which results negative values for long term variance. If time varying volatility clustering (periods of high volatility is a consequence of periods of high volatility and vice versa) presents in the time series data, we confirm the presence of ARCH effect in the time series. The following formula used to calculate the variance of return using ARCH model. $\sigma_{n}^{2}=\omega+\sum_{i=1}^{m} \alpha_{i} u_{n-1}^{2}$ where, $\omega=\gamma \mathrm{V}_{\mathrm{L}}$ and $\gamma+\sum_{\mathrm{i}=1}^{\mathrm{m}} \alpha_{\mathrm{i}}$ $=1$. The discussion of $\omega$ and $\sum_{\mathrm{i}=1}^{\mathrm{m}} \alpha_{\mathrm{i}}$ is similar as illustrates in the GARCH $(\mathrm{p}, \mathrm{q})$ process.

\subsection{Standard Deviation}

Finally we calculate year wise standard deviation of the daily return to examine the rate of variation of return of DGEN. We used standard deviation further in our study to confirm the results of GARCH (p, q) and ARCH(m) process confidently. Since the probability is equal of a finite time series when $\mathrm{x}_{1}, \mathrm{x}_{2}, \mathrm{x}_{3} \ldots \ldots \mathrm{x}_{\mathrm{n}}$ is a random variable, the standard deviation is $\sigma=\sqrt{\frac{1}{\mathrm{~N}} \sum_{\mathrm{i}=1}^{\mathrm{N}}\left(\mathrm{x}_{\mathrm{i}}-\mu\right)^{2}}$ where $\mu=\frac{1}{\mathrm{~N}} \sum_{\mathrm{i}=1}^{\mathrm{N}} \mathrm{x}_{\mathrm{i}}$.

\subsection{Data Collection and Descriptive Statistics Analysis}

We examine the daily DSE general index (DGEN) data from $1^{\text {st }}$ January 2002 to $30^{\text {th }}$ July, 2013. We have select this time period because DGEN index had continued till $30^{\text {th }}$ July, 2013. Later they had converted to DSES with different index model so we limit our analysis up to $30^{\text {th }} \mathrm{July}$, 2013. The total data set is then divided into year wise observation for volatility calculation. The following steps we consider to attain the objective of the study.

Step: 1 Calculation of the daily log return using the following formula:

$\mathrm{u}_{\mathrm{i}}=\ln \frac{\mathrm{s}_{\mathrm{i}}}{\mathrm{S}_{\mathrm{i}-1}}$ (the formula have already discussed).

Step: 2 Descriptive statistics of the daily return is illustrates in Table 1 and Figure 1 and 2 to analyze the distributional properties of the index return. 

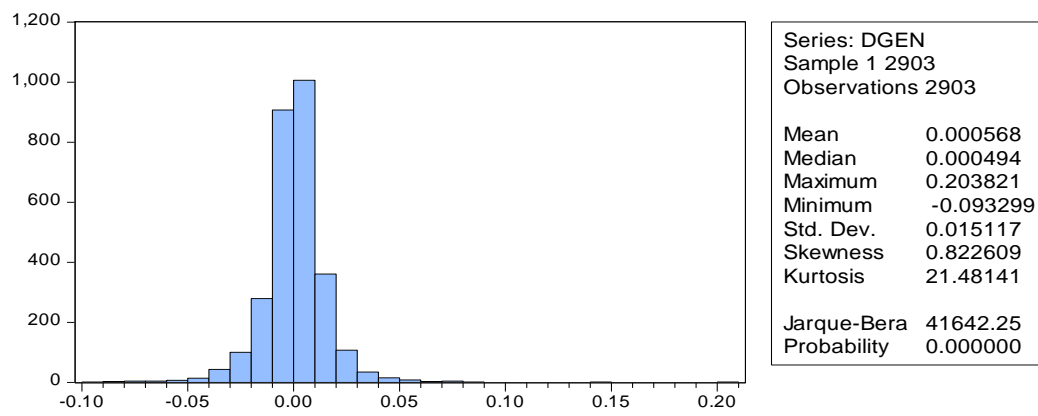

Figure 1. DGEN index return (2002-2013)

The descriptive statistics presented in the Table 1 is the overall scenario of DGEN index from 2002 to 2013 (July). It shows the mean return of the entire period is .06\% and the maximum and minimum return is $20.38 \%$ $\left(16^{\text {th }}\right.$ November, 2009) and $-9.33 \%$ (10th January, 2011) respectively. This is a notable signal of major volatility phase, which occurred inside this two date. The positive skewness, excess kurtosis and the p-value of Jarque-Bera test statistics is significant $(\mathrm{P}<.05)$ to reject the normality of the data set. However, emerging markets return is usually abnormal and since we are calculating the volatility (the variation of change) of an hardly weak form efficient market, Siddikke and Nahar (2015), abnormal data set is usual for this studies.

Table 1. Month wise descriptive statistics

\begin{tabular}{|c|c|c|c|c|c|c|c|c|c|c|c|c|}
\hline DGEN (month wise) & 2002 & 2003 & 2004 & 2005 & 2006 & 2007 & 2008 & 2009 & 2010 & 2011 & 2012 & 2013 \\
\hline Mean & $0.01 \%$ & $0.05 \%$ & $0.27 \%$ & $-0.07 \%$ & $-0.02 \%$ & $0.27 \%$ & $-0.03 \%$ & $0.20 \%$ & $0.25 \%$ & $-0.20 \%$ & $-0.10 \%$ & $0.03 \%$ \\
\hline Median & $-0.03 \%$ & $0.02 \%$ & $0.27 \%$ & $-0.03 \%$ & $-0.09 \%$ & $0.32 \%$ & $0.06 \%$ & $0.03 \%$ & $0.29 \%$ & $-0.21 \%$ & $-0.19 \%$ & $0.08 \%$ \\
\hline $\operatorname{Max}$ & $2.43 \%$ & $4.27 \%$ & $3.41 \%$ & $5.76 \%$ & $3.41 \%$ & $4.63 \%$ & $3.78 \%$ & $20.38 \%$ & $3.91 \%$ & $14.48 \%$ & $8.71 \%$ & $4.27 \%$ \\
\hline Min & $-1.70 \%$ & $-3.68 \%$ & $-4.96 \%$ & $-7.36 \%$ & $-2.75 \%$ & $-3.48 \%$ & $-4.00 \%$ & $-3.52 \%$ & $-6.96 \%$ & $-9.33 \%$ & $-7.01 \%$ & $-5.02 \%$ \\
\hline Std.Dev. & $0.62 \%$ & $0.77 \%$ & $1.06 \%$ & $1.38 \%$ & $1.09 \%$ & $1.23 \%$ & $1.31 \%$ & $1.70 \%$ & $1.21 \%$ & $2.99 \%$ & $2.08 \%$ & $1.47 \%$ \\
\hline Skewn & 0.250 & 0.430 & -0.440 & -0.507 & 0.178 & 0.070 & 0.104 & 6.955 & -1.088 & 0.344 & 0.113 & -0.358 \\
\hline Kurtos & 4.030 & 9.281 & 5.311 & 9.868 & 3.219 & 3.826 & 3.659 & 83.027 & 7.993 & 5.836 & 4.773 & 4.182 \\
\hline Jarque-Bera & 15.63 & 477.31 & 67.50 & 516.10 & 1.66 & 6.90 & 4.70 & 66802.21 & 300.36 & 83.05 & 31.56 & 11.29 \\
\hline P-valu & 0.000 & 0.000 & 0.000 & 0.000 & 0.437 & 0.032 & 0.095 & 0.000 & 0.000 & 0.000 & 0.000 & 0.004 \\
\hline Observations & 286 & 285 & 265 & 257 & 227 & 236 & 236 & 243 & 243 & 234 & 237 & 142 \\
\hline
\end{tabular}

The month wise descriptive statistics displayed in Table 1 confirm the following distributional properties of the year wise return. Firstly, the highest average daily return was in $2007(.27 \%)$ and the lowest average daily return was in $2011(-.20 \%)$. Secondly, the skewness of 2006, 2007 and 2008 are $.17, .07, .10$ which are near to zero and the kurtosis of the same years are approximately 3 express just about the normality of return. Thirdly, the p-value of Jarque-Bera test statistics in 2006 and 2008 ( $p>.05$ ) confirms the normality of return in both years. Finally in Figure 2, the maximum standard deviation of return is in $2011(2.99 \%)$ followed by $2012(2.08 \%)$ replicate the mostly volatile period of the study.

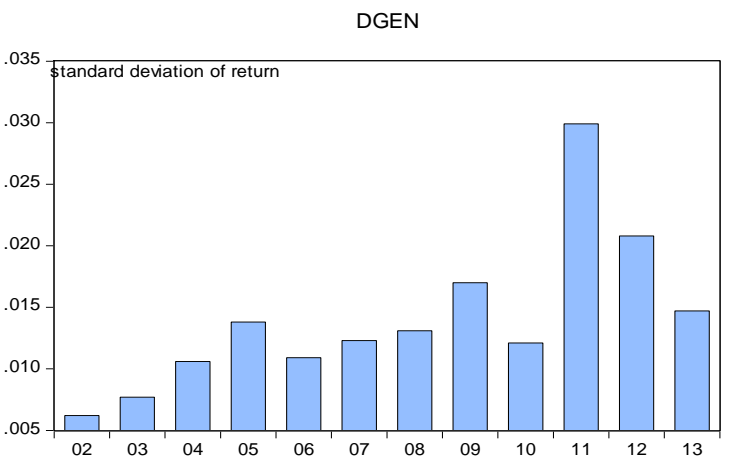

Figure 2. Standard deviation of return (2002-2013) 
Step: 3 Graphical analysis of year wise market Volatility.

The graphical representation displayed in Figure 3 plots the year wise daily return of DGEN index. We found a clear evidence of clustering volatility in each year except in 2003 and 2009 which signals that high volatility is inclined to follow by high volatility and low volatility is inclined to follow by low volatility. A huge unanticipated positive variation happened at the end of $2009\left(16^{\text {th }}\right.$ November, $\left.2009,20.38 \%\right)$ after a relatively consistent upwards trends in previous couple of years. The similar shock again attack at the end of 2010 and continued till the first half of 2011 and causes the highest market volatility of last decade.

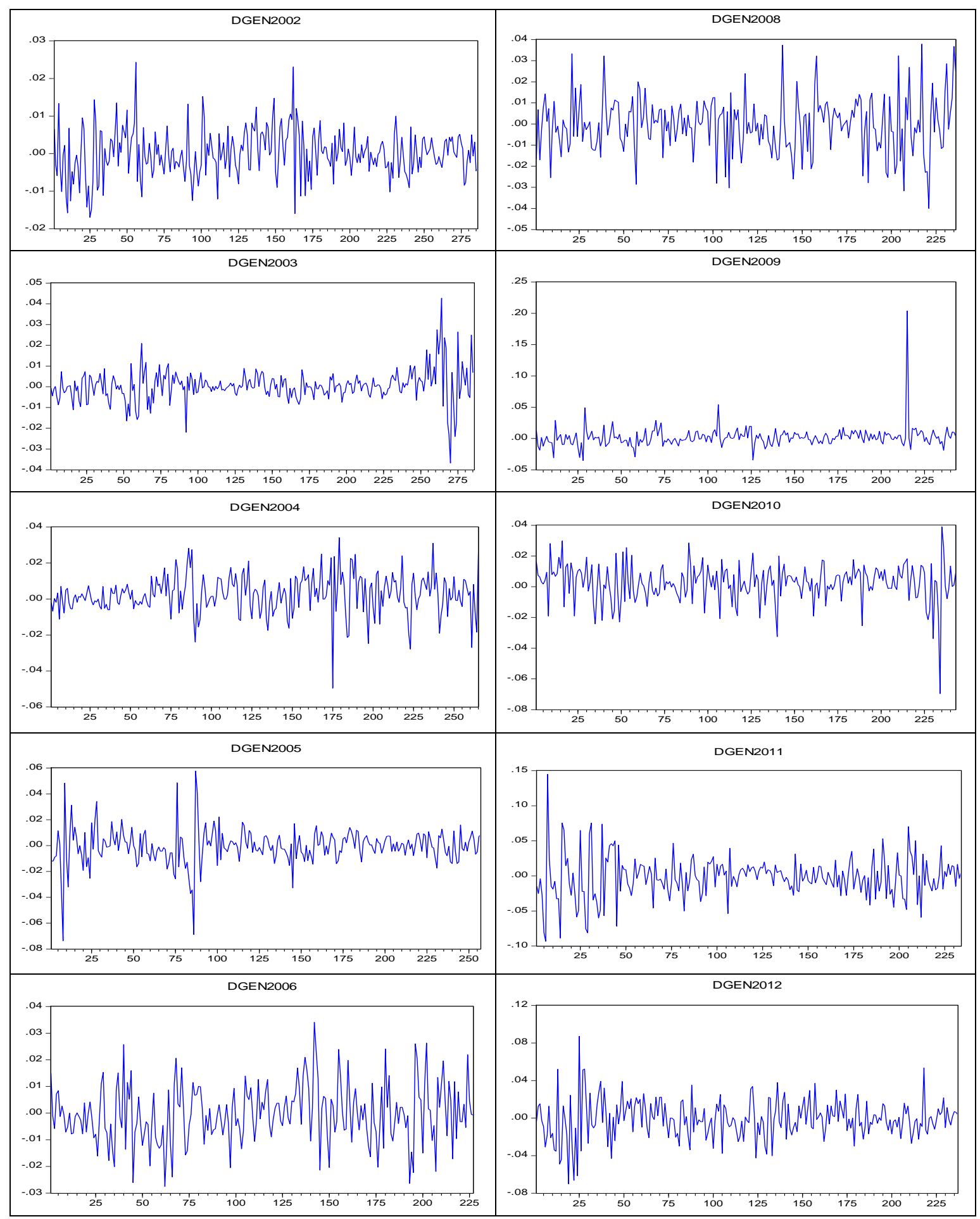




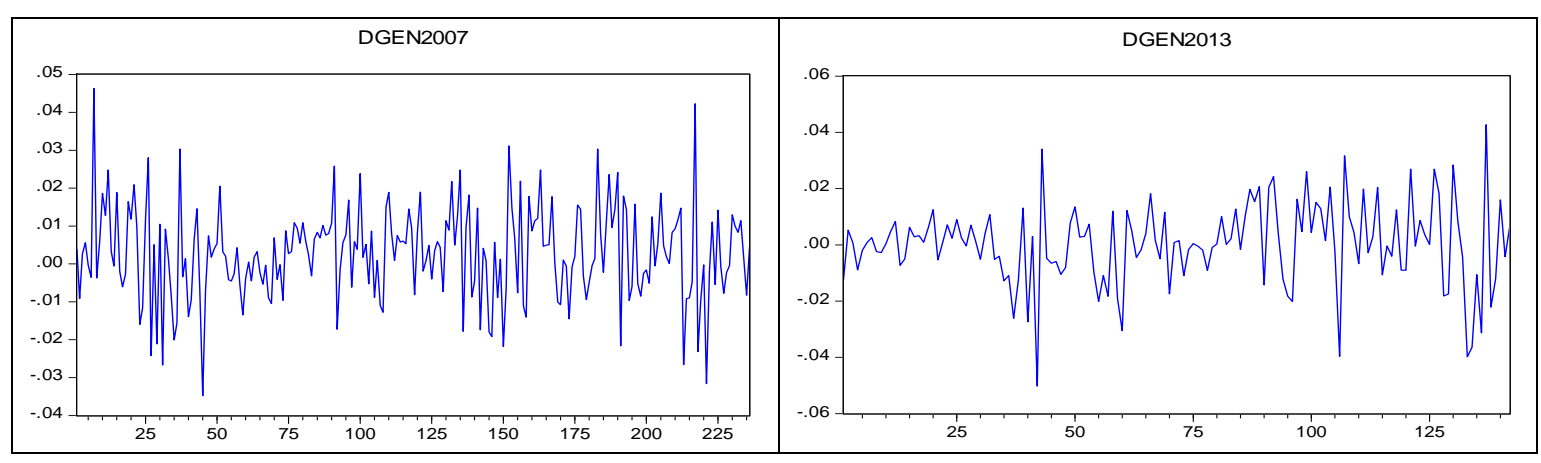

Figure 3. Yearly DGEN index return (2002-2013)

Step: 4 Stationary test of the market return using Autocorrelation and Augmented Dickey Fuller (ADF) test.

A time series data is said to be stationary if the mean and variance of return are constant over time which indicate the absence of positive as well as negative pattern of the time series return. Autocorrelation is a primary mathematical tool used to detect the existence of any predictable pattern in the time series data. It shows the correlation of the values of a single variable at different time lag. If autocorrelation value gradually increase or decrease, a predictable pattern exists in the return series, state non-stationary of return. As long as the value of autocorrelation is close to zero at different lag, the time series return is stationary. However a trend of autocorrelation may direct inefficient capital market but it also signals a relatively smooth market compare to high fluctuations of autocorrelation which direct a volatile capital market.

Table 3. Autocorrelation

\begin{tabular}{lrrrrrrrrrrrr}
\hline DGEN & $\mathbf{2 0 0 2}$ & $\mathbf{2 0 0 3}$ & $\mathbf{2 0 0 4}$ & $\mathbf{2 0 0 5}$ & $\mathbf{2 0 0 6}$ & $\mathbf{2 0 0 7}$ & $\mathbf{2 0 0 8}$ & $\mathbf{2 0 0 9}$ & $\mathbf{2 0 1 0}$ & $\mathbf{2 0 1 1}$ & $\mathbf{2 0 1 2}$ & $\mathbf{2 0 1 3}$ \\
\hline Lag-1 & $15.8 \%$ & $25.4 \%$ & $13.6 \%$ & $8.5 \%$ & $18.3 \%$ & $2.6 \%$ & $7.1 \%$ & $2.8 \%$ & $-2.1 \%$ & $0.3 \%$ & $-5.0 \%$ & $-3.1 \%$ \\
Lag-2 & $-4.1 \%$ & $10.7 \%$ & $-2.9 \%$ & $-9.7 \%$ & $-6.6 \%$ & $-5.0 \%$ & $-8.1 \%$ & $-9.3 \%$ & $-17.3 \%$ & $-8.0 \%$ & $4.9 \%$ & $3.3 \%$ \\
Lag-3 & $6.4 \%$ & $15.2 \%$ & $4.4 \%$ & $-0.6 \%$ & $-5.0 \%$ & $8.1 \%$ & $-12.8 \%$ & $3.8 \%$ & $7.3 \%$ & $-11.2 \%$ & $9.5 \%$ & $5.2 \%$ \\
Lag-4 & $12.5 \%$ & $2.3 \%$ & $-13.5 \%$ & $6.3 \%$ & $11.2 \%$ & $3.7 \%$ & $2.0 \%$ & $3.7 \%$ & $10.3 \%$ & $-3.0 \%$ & $4.9 \%$ & $3.3 \%$ \\
Lag-5 & $3.1 \%$ & $5.1 \%$ & $-3.9 \%$ & $-1.7 \%$ & $4.0 \%$ & $5.8 \%$ & $9.8 \%$ & $8.6 \%$ & $-0.8 \%$ & $-7.5 \%$ & $7.4 \%$ & $16.2 \%$ \\
Lag-6 & $3.1 \%$ & $-9.9 \%$ & $-0.2 \%$ & $0.2 \%$ & $-1.2 \%$ & $9.2 \%$ & $-4.8 \%$ & $2.2 \%$ & $4.0 \%$ & $2.4 \%$ & $-18.1 \%$ & $-4.7 \%$ \\
Lag-7 & $9.5 \%$ & $-7.5 \%$ & $6.8 \%$ & $-4.2 \%$ & $1.3 \%$ & $2.9 \%$ & $0.3 \%$ & $0.2 \%$ & $6.7 \%$ & $-2.6 \%$ & $-3.1 \%$ & $-1.2 \%$ \\
Lag-8 & $8.6 \%$ & $0.2 \%$ & $6.4 \%$ & $-6.2 \%$ & $0.2 \%$ & $-9.0 \%$ & $4.5 \%$ & $4.3 \%$ & $-2.9 \%$ & $3.3 \%$ & $1.7 \%$ & $-9.8 \%$ \\
Lag-9 & $2.4 \%$ & $-1.2 \%$ & $3.4 \%$ & $4.6 \%$ & $10.3 \%$ & $2.7 \%$ & $6.4 \%$ & $-0.5 \%$ & $-4.8 \%$ & $12.3 \%$ & $5.2 \%$ & $-5.1 \%$ \\
Lag-10 & $-2.7 \%$ & $-1.4 \%$ & $7.5 \%$ & $-0.7 \%$ & $0.2 \%$ & $-5.3 \%$ & $-1.5 \%$ & $-3.6 \%$ & $4.8 \%$ & $0.8 \%$ & $2.6 \%$ & $10.9 \%$ \\
\hline
\end{tabular}

*significant @ 5\% level.

The autocorrelation of lag 1 shows a minor predictable pattern from 2002 to 2006 and it becomes insignificant from 2007 and onwards implies the stationary of return as well as the variation of return in both directions. The highest autocorrelation was found in 2003 (25.4\%) followed by 15.8\% in 2002 notice a high predictable pattern exist at the start of the period also. At lag 2, a negative autocorrelation pattern had prevailed from 2004-2011 and a significant negative pattern was seen from 2007 to 2010 which signals investors, arbitragers and gamblers trends of index value for gaining abnormal profit. Apart from this, no significant predictable pattern exist in the rest other return lag confirms the stationary of return.

Augmented Dickey-Fuller (ADF) test is being applied to check the presence of unit root in the market return. The ADF test with trend and trend and intercept at levels is suitable to examine the null hypothesis of unit root presence in the return series against the alternative, the series is stationary. The lag length of the analysis is based on the Akaike information criterion (AIC). Since ADF test allows a higher order autoregressive process, the lag selection procedure starts from a reasonable higher order and fix on lag which shows lowest AIC values. If the test statistics is less than the test critical value we reject the null hypothesis and confirm the stationary of market return. 
Table 4. Augmented Dickey Fuller (ADF) test

\begin{tabular}{|c|c|c|c|c|c|c|c|c|c|c|c|c|}
\hline Test Statistics & 2002 & 2003 & 2004 & 2005 & 2006 & 2007 & 2008 & 2009 & 2010 & 2011 & 2012 & 2013 \\
\hline Intercept & -14.35 & -12.92 & -13.96 & -14.64 & -12.49 & -14.87 & -14.14 & -15.08 & -13.18 & -15.15 & -16.08 & -12.18 \\
\hline $\begin{array}{l}\text { Trend and } \\
\text { Intercept }\end{array}$ & -14.38 & -13.22 & -14.00 & -14.67 & -12.68 & -14.84 & -14.11 & -15.46 & -13.17 & -15.15 & -16.07 & -12.18 \\
\hline
\end{tabular}

*significant @ 1\% and 5\% level.

The ADF test statistics exhibits in Table.4 completely reject the null hypothesis and confirm the stationary of return in each year. The test statistics of both formulas for each year is significantly below than the test critical values of $1 \%$ and $5 \%$ level of significance and their p- values are zero in all test.

\section{Results and Discussion}

The empirical findings of GARCH $(1,1)$ process displayed in Table 5 confirm that except 2003, 2004 and 2013 the sum of parameter value is less than one i.e. $(\alpha+\beta)<1$ implying that long term variance will be positive and GARCH $(1,1)$ process can capture the true pictures of yearly volatility for the remaining years. However the intercept term of 2003, 2005 and 2010 is statistically significant at 5\% level indicate the weight assigned to long term variance in remaining years may mislead the volatility calculation. However the weight assigned to long term variance is always very small so it has only a minor impact on the true pictures of market volatility which is not too significant in GARCH $(1,1)$ process. The parameter $\alpha$ is statistically significant in each year except 2007 and the parameter $\beta$ is also significant in each year except 2010 strongly allow the $\operatorname{GARCH}(1,1)$ process for measuring volatility.

In Table 6, we put different values of $\mathrm{p}, \mathrm{q}$ in the $\operatorname{GARCH}(\mathrm{p}, \mathrm{q})$ process and validate $\operatorname{GARCH}(2,3)$ process for volatility calculation in 2003 on the basis of minimum Schwarz Information Criterion (SIC) which offer $(\alpha+\beta)<$ 1 but fails to get the sum of parameter value less than one in 2004 and 2013. So we apply ARCH model in year 2004 and 2013 for volatility calculation.

Table 5. Volatility calculations using $(\mathrm{GARCH}(1,1)$ process

\begin{tabular}{|c|c|c|c|c|c|c|c|c|c|}
\hline Year & GARCH Model & $\omega$ & $\alpha$ & $\boldsymbol{\beta}$ & $\gamma$ & $(\alpha+\beta)$ & Variance & Volatility & SIC \\
\hline \multirow{2}{*}{2002} & \multirow{2}{*}{ (GARCH 1,1) } & 0.000002 & 0.200713 & 0.7569 & 0.0424 & 0.9576 & $0.0047 \%$ & $0.68 \%$ & -7.403 \\
\hline & & 0.087 & 0.001 & 0.000 & & & & & \\
\hline \multirow{2}{*}{2003} & \multirow{2}{*}{ (GARCH 1,1) } & 0.000001 & 0.157543 & 0.8441 & -0.0016 & 1.0016 & $-0.0521 \%$ & $-2.28 \%$ & -7.396 \\
\hline & & 0.0289 & 0.000 & 0.000 & & & & & \\
\hline \multirow{2}{*}{2004} & \multirow{2}{*}{ (GARCH 1,1) } & 0.000001 & 0.117138 & 0.8940 & -0.0111 & 1.0111 & $-0.0066 \%$ & $-0.81 \%$ & -6.34 \\
\hline & & 0.4607 & 0.000 & 0.000 & & & & & \\
\hline \multirow{2}{*}{2005} & \multirow{2}{*}{ (GARCH 1,1) } & 0.000029 & 0.450691 & 0.3801 & 0.1692 & 0.8308 & $0.0170 \%$ & $1.30 \%$ & -6.15 \\
\hline & & 0.003 & 0.000 & 0.001 & & & & & \\
\hline \multirow{2}{*}{2006} & \multirow{2}{*}{ (GARCH 1,1) } & 0.000008 & 0.113648 & 0.8195 & 0.0668 & 0.9332 & $0.0125 \%$ & $1.12 \%$ & -6.23 \\
\hline & & 0.202 & 0.021 & 0.000 & & & & & \\
\hline \multirow{2}{*}{2007} & \multirow{2}{*}{ (GARCH 1,1) } & 0.000020 & 0.087472 & 0.7787 & 0.1339 & 0.8661 & $0.0152 \%$ & $1.23 \%$ & -5.89 \\
\hline & & 0.210 & 0.168 & 0.000 & & & & & \\
\hline \multirow{2}{*}{2008} & \multirow{2}{*}{ (GARCH 1,1) } & 0.000014 & 0.121493 & 0.8081 & 0.0704 & 0.9296 & $0.0195 \%$ & $1.40 \%$ & -5.78 \\
\hline & & 0.106 & 0.033 & 0.000 & & & & & \\
\hline \multirow{2}{*}{2009} & \multirow{2}{*}{ (GARCH 1,1) } & 0.000110 & -0.010134 & 0.7362 & 0.2740 & 0.7260 & $0.0402 \%$ & $2.00 \%$ & -5.19 \\
\hline & & 0.254 & 0.000 & 0.002 & & & & & \\
\hline \multirow{2}{*}{2010} & \multirow{2}{*}{ (GARCH 1,1) } & 0.000055 & 0.487926 & 0.2095 & 0.3026 & 0.6974 & $0.0183 \%$ & $1.35 \%$ & -6.04 \\
\hline & & 0.000 & 0.000 & 0.102 & & & & & \\
\hline \multirow{2}{*}{2011} & \multirow{2}{*}{ (GARCH 1,1) } & 0.000018 & 0.159530 & 0.8101 & 0.0304 & 0.9696 & $0.0596 \%$ & $2.44 \%$ & -4.49 \\
\hline & & 0.203 & 0.001 & 0.000 & & & & & \\
\hline \multirow{2}{*}{2012} & \multirow{2}{*}{ (GARCH 1,1) } & 0.000027 & 0.136890 & 0.7949 & 0.0682 & 0.9318 & $0.0394 \%$ & $1.99 \%$ & -5.01 \\
\hline & & 0.153 & 0.026 & 0.000 & & & & & \\
\hline \multirow{2}{*}{2013} & \multirow{2}{*}{ (GARCH 1,1) } & 0.000005 & 0.307436 & 0.7260 & -0.0334 & 1.0334 & $-0.0148 \%$ & $-1.21 \%$ & -5.72 \\
\hline & & 0.374 & 0.006 & 0.000 & & & & & \\
\hline
\end{tabular}

\footnotetext{
* The parenthesis given is the $\mathrm{p}$-value.
} 
The findings of the GARCH $(1,1)$ process in Table 5 reveled a huge volatility episode in 2009 to 2012 . The highest volatility is found in 2011 (2.44\% per day) followed by 2009 and 2012 (2\% per day). From 2005 to 2008 it lies within $1.12 \%$ to $1.40 \%$ and maintain a tolerable rang of market volatility. Afterwards drastic rising trends continued and finally cause the huge market crash in the first half of 2011. The index value rising was quite unusual due to artificial value creation of some specific securities but the regulatory agencies like DSE, BSEC and Bangladesh Bank failed to control in that time. The Table 6 illustrates the GARCH $(2,3)$ process in 2003 and reveals the market volatility is $1.77 \%$ per day which is significantly higher than $2002(.68 \%$ per day) specify a volatile phase with structural breaks in Index value. The minimum SIC value of GARCH $(2,3)$ process authenticate the process also. But in 2004 and 2013 we have put several values of $\mathrm{p}$ and $\mathrm{q}$ but no process are giving $\sum(\boldsymbol{\alpha}+\boldsymbol{\beta})<1$ so findings exhibit negative variance and volatility. Since negative variance is not valid the GARCH $(\mathrm{p}, \mathrm{q})$ process are not applicable for volatility calculation in those year.

Table 6. GARCH (p, q) model for volatility calculation

\begin{tabular}{|c|c|c|c|c|c|c|c|c|c|c|c|}
\hline Year & $\begin{array}{c}\text { GARCH } \\
\text { Model }\end{array}$ & $\omega$ & $\alpha$ & $\alpha(-1)$ & $\boldsymbol{\beta}$ & $\beta(-1)$ & $\beta(-2)$ & $(\alpha+\beta)$ & Variance & Volatility & SIC \\
\hline \multirow{12}{*}{2003} & $\operatorname{GARCH}(2,3)$ & 0.000001 & 0.227064 & -0.0952 & 1.4800 & -1.1534 & 0.5389 & 0.9974 & 0.00031 & $1.77 \%$ & -5.87 \\
\hline & & 0.042 & 0.001 & 0.274 & 0.000 & 0.000 & 0.000 & & & & \\
\hline & $\operatorname{GARCH}(\mathbf{1}, \mathbf{1})$ & 0.000002 & 0.1771 & & 0.864966 & & & 1.0421 & -0.00004 & $-0.60 \%$ & -6.43 \\
\hline & & 0.299 & 0.0265 & & 0.000 & & & & & & \\
\hline & $\operatorname{GARCH}(1,2)$ & 0.000 & 0.148 & & 1.099 & -0.2118 & & 1.0345 & 0.000 & $-0.59 \%$ & -6.370 \\
\hline & & 0.458 & 0.355 & & 0.311 & 0.829 & & & & & \\
\hline & $\operatorname{GARCH}(2,1)$ & 0.0000007 & 0.296 & -0.156 & 0.865 & & & 1.0047 & -0.00015 & $-1.209 \%$ & -7.38 \\
\hline & & 0.034 & 0.003 & 0.111 & 0.000 & & & & & & \\
\hline & $\operatorname{GARCH}(2,2)$ & 0.000 & 0.296 & -0.175 & 0.973 & -0.0898 & & 1.0037 & -0.00016 & $-1.275 \%$ & -7.36 \\
\hline & & 0.219 & 0.003 & 0.170 & 0.070 & 0.843 & & & & & \\
\hline & $\operatorname{GARCH}(1,1)$ & 0.000 & 0.11714 & & 0.893978 & & & 1.0111 & -0.00007 & $-0.815 \%$ & -6.34 \\
\hline & & 0.461 & 0.000 & & 0.000 & & & & & & \\
\hline \multirow{6}{*}{2004} & $\operatorname{GARCH}(1,2)$ & 0.000001 & 0.20907 & & 0.168174 & 0.6442 & & 1.0215 & -0.00005 & $-0.71 \%$ & -6.34 \\
\hline & & 0.498 & 0.000 & & 0.283 & 0.000 & & & & & \\
\hline & $\operatorname{GARCH}(\mathbf{2}, \mathbf{1})$ & 0.000001 & 0.29333 & -0.23254 & 0.942141 & & & 1.0029 & -0.00020 & $-1.41 \%$ & -6.34 \\
\hline & & 0.312 & 0.000 & 0.004 & 0.000 & & & & & & \\
\hline & $\operatorname{GARCH}(2,2)$ & 0.000001 & 0.30628 & -0.18458 & 0.649017 & 0.2396 & & 1.0103 & -0.00008 & $0.88 \%$ & -6.32 \\
\hline & & 0.446 & 0.000 & 0.089 & 0.049 & 0.397 & & & & & \\
\hline \multirow{12}{*}{2013} & $\operatorname{GARCH}(2,3)$ & 0.000002 & 0.20112 & 0.05571 & 0.17635 & -0.2809 & 0.8620 & 1.0143 & -0.000002 & $0.15 \%$ & -6.34 \\
\hline & & 0.245 & 0.000 & 0.168 & 0.000 & 0.000 & 0.000 & & & & \\
\hline & $\operatorname{GARCH}(1,1)$ & 0.000005 & 0.30744 & & 0.725977 & & & 1.0334 & -0.000148 & $-1.21 \%$ & -5.72 \\
\hline & & 0.374 & 0.006 & & 0.000 & & & & & & \\
\hline & $\operatorname{GARCH}(1,2)$ & 0.000006 & 0.2480 & & 1.1155 & -0.3456 & & 1.0179 & -0.000314 & $-1.77 \%$ & -5.69 \\
\hline & & 0.244 & 0.022 & & 0.000 & 0.097 & & & & & \\
\hline & $\operatorname{GARCH}(2,1)$ & 0.000 & 0.19515 & 0.21516 & 0.622632 & & & 1.0329 & -0.000256 & $-1.60 \%$ & -5.69 \\
\hline & & 0.320 & 0.249 & 0.229 & 0.000 & & & & & & \\
\hline & $\operatorname{GARCH}(2,2)$ & 0.00001 & 0.18588 & 0.18115 & 0.79350 & -0.13276 & & 1.0278 & -0.000286 & $-1.69 \%$ & -5.66 \\
\hline & & 0.349 & 0.263 & 0.506 & 0.208 & 0.769 & & & & & \\
\hline & $\operatorname{GARCH}(2,3)$ & 0.000008 & 0.19001 & 0.31401 & 0.581311 & -0.292698 & 0.2653 & 1.0579 & -0.000145 & $-1.20 \%$ & -5.628 \\
\hline & & 0.378 & 0.227 & 0.153 & 0.119 & 0.548 & 0.350 & & & & \\
\hline
\end{tabular}

* The parenthesis given is the p-value.

So we applied ARCH (m) model in 2004 and 2013 and get the average per day volatility is $1.10 \%$ and $1.46 \%$ respectively. The parameters value is significant enough to accept the results. 
Table 7. ARCH (m) model

\begin{tabular}{ccccc}
\hline Year & $\boldsymbol{\omega}$ & $\boldsymbol{\alpha}$ & Variance & Volatility \\
\hline 2004 & 0.000076 & 0.370806 & 0.00012 & $1.10 \%$ \\
& 0.000 & 0.000 & & $1.46 \%$ \\
& 0.000162 & 0.234983 & 0.000212 & \\
\end{tabular}

* The parenthesis given is the p-value.

The summery of the findings presented in Table 8 confirm a sharp rise and fall of market volatility at the beginning of the period and became relatively calmer later but continued increasing till mid-2009. Most of the securities price movement were increasing continuously in that period which causes artificial value creation and create excess demands to the investors. The securities ware overpriced so rate of market volatility continued rising and finally crashes the market entirely within November 2010 to April, 2011. The peak position of the graphical display of Table 8 shows the highest volatility per day (2.44\%) in 2011. After that continuous decline of market volatility is observed due to intervention of government and regulatory agency.

Table 8. Summery of the findings

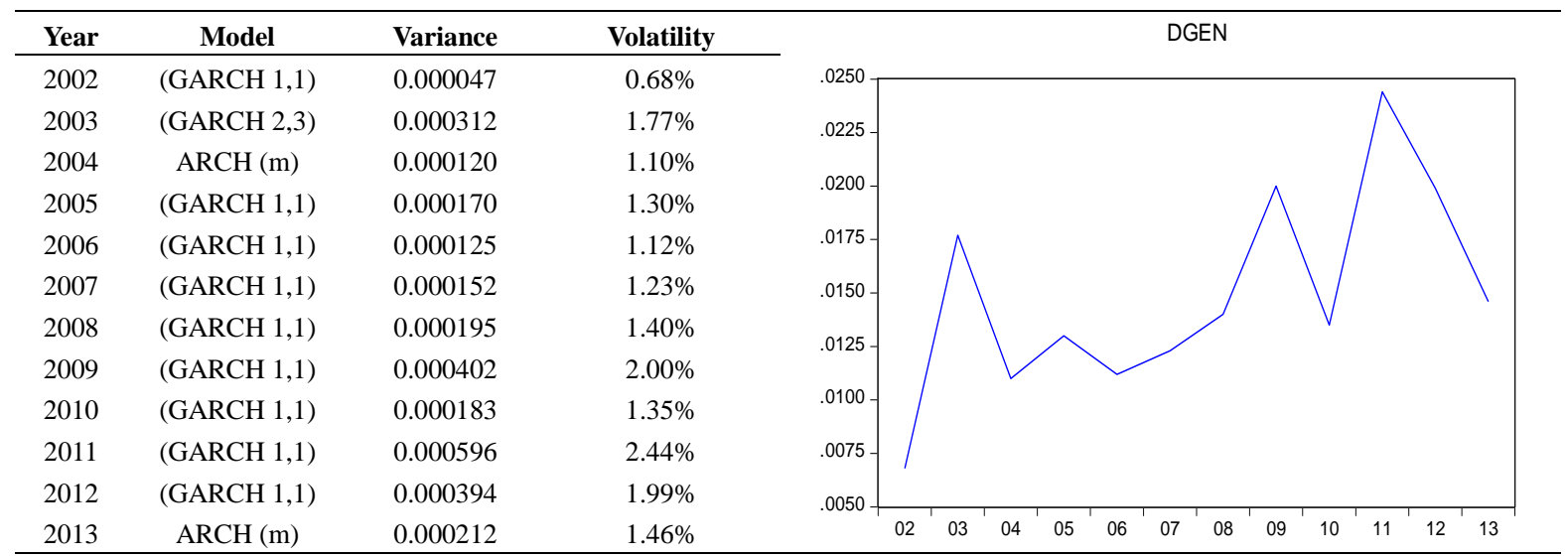

\section{Conclusions}

Volatility in stock markets is very much usual. Without volatility potential investors doesn't want to invest in capital market because of no chance of gain. But the volatility levels require keeping in a tolerable range for the average investors. Otherwise they will lose their faith continuously to the stock markets. The stock exchange authority must be careful in monitoring and forecasting the trends of volatility of DSE. In our study we have recognized tolerable market volatility from 2002 to 2009. In that period, the standard deviation of the market return was increasing a little from 2002 to 2005 and extensively increased from 2006 to 2009 implies volatility was increasing at an increasing rate in both episode which is good for small and medium investors. But a sharp fall from 2005 to 2006 signifies volatility increased at decreasing rate. The market becomes rudely volatile from 2010 to 2011 and then declined tremendously till it became weak form efficient, Siddikee and Begum (2015).

The DSE crash of 1996 and 2010-11 has already becomes a most talkative and political issues in Bangladesh. When any symptoms of volatility are sighted, immediate action by the regulatory bodies should be taken to avoid the unexpected market falls. It will be effective to the regulatory authorities to identify the potential factors responsible for market volatility earlier and quickly disseminate it to the investors. The authority may take necessary measures to make available the relevant information of the companies who had experienced recently a high volatility in their stock prices.

We expect the findings of this study will be useful for the potential investor's for investment in DSE. Also this study will give emphasize to investigate the factors affecting volatility and their relative impact on stock indexes.

\section{References}

Abu, T., \& Mollik, M. K. (2009). Risk-Return Trade-off in Emerging Markets: Evidence from Dhaka Stock Exchange Bangladesh. 22nd Australasian Finance and Banking Conference 2009. 
http://dx.doi.org/10.14453/aabfj.v9i1.6

Ainul Islam, M. K. (2005). Tests of Weak-Form Efficiency of the Dhaka Stock Exchange. Journal of Business Finance and Accounting, 1613-1623. http://dx.doi.org/10.1111/j.0306-686X.2005.00642.x

Ariff, M. (1986). Announcement Effects and Market Efficiency in a Thin Market: An Empirical Application to the Singapore Equity Market. Asia Pacific Journal of Management, 243-267.

Begum, N., \& Siddikee, M. N. (2015). Is Pharmaceuticles Industry Efficient? Evidence from Dhaka Stock Exchange. Accounting and Finance Research, 46-54. http://dx.doi.org/10.5430/afr.v4n3p46

Bollerslev, T. (1986). Generalized Autoregrresive Conditional Heteroskedasticity. Journal of Econometrics. http://dx.doi.org/10.1016/0304-4076(86)90063-1

Easton, S. A. (1989). The Impact of Unexpected Earnings and Dividends on Abnormal Returns to Equity. Accounting and Finance, 1-19. http://dx.doi.org/10.1111/j.1467-629X.1989.tb00152.x

Gordon, M. J. (1959). Dividends, Earnings, and Stock Prices. The Review of Economics and Statistics, 99-105. http://dx.doi.org/10.2307/1927792

Kabir Hasan, M. I. (1999). Market Efficiency, Time Varying Volatility and Equity Returns in Bangladesh Stock Market. Applied Financial Economics, 1393-1407.

Kashif Hamid, M. T. (2010). Testing the Weak form of Efficient Market Hypothesis: Empirical Evidence from Asia-Pacific Markets. International Research Journal of Finance and Economics, 121-133.

Officer, R. (1973). The variability of the Market Factor of New York Stock Exchange. Journal of Business, 434-453. http://dx.doi.org/10.1086/295551

Ogden, J. (1994). A Dividend Payment Effect in Stock Returns. Financial Review, 345-369. http://dx.doi.org/10.1111/j.1540-6288.1994.tb00401.x

P. H. L. (1982). The Effects of Dividend Policy on Changes in Stockholders' Wealth. USA: Graduate School of Saint Louis University.

R. E. (1982). Autoregressive Conditional Heteroskcedasticity with estimates of the variance of United Kingdom Inflation. Econometrica, 1343-1376.

Rajani Mala, M. R. (2007). Measuring Stock Market Volatility in an Emerging Economy. International Research Journal of Finance and Econoics.

SSH Chowdhury, A. T. (2006). Does Predicted Macroeconomic Volatility Influence Stock Market Volatility? Evidence from, the Bangladesh Capital Market. 4th international conference on accounting and finance in transition (ICAFT 2006), pp. 1-15.

Stevens, M. L. (1989). Capital market Valuation of Dividend Policy. Journal of Business Finance and Accounting, 651-661.

Syed, A., \& Bashera, M. K. (2007). Time-varying volatility and equity returns in Bangladesh stock market. Applied Financial Economics, 1393-1407.

Tsay, H. K. (2002). Dividend policy, cash flow, and investment in Japan. Pacific-Basin Finance Journal, 443-473.

\section{Copyrights}

Copyright for this article is retained by the author(s), with first publication rights granted to the journal.

This is an open-access article distributed under the terms and conditions of the Creative Commons Attribution license (http://creativecommons.org/licenses/by/3.0/). 